\title{
Metabolic Syndrome and Diabetes Risk Among Young Adult Students in the Health Sciences from Kathmandu, Nepal
}

This article was published in the following Dove Press journal:

Drug, Healthcare and Patient Safety

\author{
Manisha Sapkota $\mathbb{D}^{1, *}$ \\ Alaska Timilsinal,* \\ Mudita Shakya' \\ Tika Bahadur Thapa (D) \\ Sneha Shrestha' \\ Sushant Pokhrel (iD) \\ Nishchal Devkota ${ }^{2}$ \\ Bashu Dev Pardhe (D) \\ 'Department of Laboratory Medicine, \\ Manmohan Memorial Institute of Health \\ Sciences, Kathmandu, Nepal; \\ ${ }^{2}$ Department of Public Health, Central \\ Institute of Science and Technology, \\ Baneshwor, Nepal \\ *These authors contributed equally to \\ this work
}

Background: The widespread dissemination of unhealthy dietary habits, childhood-teenage obesity, and sedentary lifestyle in young adults has paved the way for public health burden metabolic syndrome and early onset of type 2 diabetes mellitus. The aim of this study was to assess the prevalence and risk factors for metabolic syndrome and diabetes among young adult students.

Methods: This cross-sectional study was conducted among students of age group (18 to 25 years) studying at Manmohan Memorial Institute of Health Sciences and Central Institute of Science and Technology. The diabetes risk score of each individual was calculated by the Finnish Diabetes Risk Score (FINDRISC tool). Independent risk factors for diabetes and metabolic syndrome were measured by multivariable logistic regression analysis. The p-value of $<0.05$ was considered statistically significant in this study.

Results: A total of 825 students were recruited and 739 (89.6\%) students completed the study with all the fulfilled criteria. The metabolic syndrome (Harmonized Joint Scientific Statement (HJSS) criteria) was present in $7.1 \%$, and the most prevalent defining component was low HDL-C (78\%); $74.8 \%$ of students were under low risk, $22.18 \%$ were at slightly elevated risk, $2.02 \%$ were at moderate risk, and $1.01 \%$ were at high risk of diabetes. The cardiometabolic risk factors like BMI, TC, and LDL-C were higher at a significant level $(\mathrm{p}<0.001)$ with an increased diabetes risk score. Independent lifestyle risk factor for metabolic syndrome was current smoking (AOR, 4.49, 95\% CI 1.38-14.62) whereas, an independent lifestyle risk factor for diabetes was low adherence to physical exercise (AOR, 4.81, 95\% CI, 2.90-7.99).

Conclusion: Metabolic syndrome is present, although in low numbers in young adults putting them at risk to develop diabetes in the near future. Early assessment of metabolic syndrome and diabetes risk in young may provide insights for preventive and control plans for risk population.

Keywords: metabolic syndrome, diabetes risk, young adults, Nepal

\section{Background}

The low- and middle-income countries have mirrored the trend and are experiencing a rise in non-communicable diseases (NCDs) such as metabolic syndrome (MetS), Diabetes Mellitus (DM) and cardiovascular diseases (CVDs) due to soaring urbanization accompanied by rapid lifestyle changes. ${ }^{1,2}$ Nepal, being one of the low- and middle-income countries, is experiencing a significant epidemiological transition including unplanned urbanization, poor lifestyle interventions; the
Correspondence: Bashu Dev Pardhe Department of Laboratory Medicine, Manmohan Memorial Institute of Health Sciences, Kathmandu I520I, Nepal Tel +977-0 I-403078I

Email pardhebashu@gmail.com 
increasing trend of which results in threatening health challenges. $^{2}$ The widespread dissemination of unhealthy dietary habits, childhood-teenage obesity and sedentary lifestyle in young adults has paved the way for public health burden metabolic syndrome. ${ }^{3}$ Current estimates suggest that 20-25\% of South Asians have developed MetS. ${ }^{1}$ The study of Sharma et al in Nepal has reported its prevalence to be $22.5 \%$ according to the definition of International Diabetes Federation (IDF) and 20.7\% according to National Cholesterol Education Programme Adult Treatment Panel III (NCEP ATP III) definition. ${ }^{4}$ The MetS and its subsequent clinical outcomes have a dreadful impact on the world population with millions of avoidable deaths. ${ }^{5}$ The individuals with MetS are thrice as likely to have a heart attack or stroke compared to people without the syndrome. ${ }^{6}$

MetS comprises the combination of cardiometabolic risk factors including insulin resistance, atherogenic dyslipidaemia, central obesity and hypertension which when occur together increases the risk of developing complications like heart attacks, strokes and sudden cardiac death. The World Health Organization (WHO) definition revolves around the presence of diabetes mellitus and insulin resistance as a key requirement, while the NCEP ATP III, IDF definition allows the presence of any three out of five components (hyperglycaemia, hypertension, central obesity (WC), elevated triglycerides and low high-density lipoprotein (HDL-C)) for defining MetS. ${ }^{7}$ IDF criteria is more applicable for the risk assessment of MetS in Asian population ${ }^{8}$ while, the Harmonized Joint Scientific Statement (HJSS), criteria suggested the population specific-criteria for waist circumference because cut-off values of waist circumference (WC) designed for the Western population are found to underestimate central obesity and MetS in South Asian population. ${ }^{1,9}$

It is important to pay regard that MetS remains undiagnosed for many years. By the time when they are diagnosed, they are already plagued with complications. People with MetS are found more prone to develop T2DM with fivefold greater risk than people without MetS. ${ }^{6}$ Individuals with this inter-connected metabolic disorder are subjected to micro and macro-vascular damages. ${ }^{10}$ Diabetes risk has been evaluated using various tools among which Finnish Diabetes Risk Score (FINDRISC) is a simple, non-invasive screening tool holding a clear picture of risk factors associated with diabetes. ${ }^{11}$ Having numerous validation studies regarding this tool, it can be beneficial for the prediction of future diabetes. ${ }^{11,12}$

Young adults (18-25 years) are less prone to have metabolic syndrome. Besides, they are also known to skip meals, consume unhealthy foods or do binge eating, which puts them at risk for weight gain, insulin resistance and early onset of T2DM. ${ }^{13}$ For this study, we chose young College going students of Health Sciences because they seem to be an optimal population to make aware of healthy diets and prevention and management of metabolic diseases. ${ }^{14}$ On that account, this study aims to find out the prevalence of MetS and diabetes risk score and its association with cardiometabolic risk in young adult Health Science College going students.

\section{Methods}

\section{Study Design and Selection Criteria}

This descriptive cross-sectional study was conducted in Manmohan Memorial Institute of Health Sciences, Kathmandu, Nepal and Central Institute of Science and Technology (CIST), Kathmandu, Nepal during the period of six months (February to July 2018). All Health Science students 572 from MMIHS and 253 from CIST studying at the Department of Laboratory Medicine, Public Health, Pharmacy, and Nursing were included in this study. Initially, all the students from each Department were approached during their break time for 20 minutes and informed about the protocol and requirement of the survey. Informed and written consent was recorded from each participant and they were interviewed and all the required lifestyle variables for this study were recorded by using standard questionnaire. Students beyond the age group of 18 to 25 years were excluded from the study. Standard questionnaire was developed based on the variables required for the FINDRISC tool. Students were interviewed and anthropometric measurements were recorded. They were suggested to provide 8 hours fasting blood sample the next morning for the biochemical measurements.

\section{Experimental Protocol}

All the anthropometric, demographic and clinical baseline characteristics from each individual were recorded using a standard questionnaire. Height was measured by using a wall scale meter with barefoot. Weight was measured by using a standard digital weighing machine to the nearest $0.1 \mathrm{~kg}$ with barefoot and minimal clothing. Body mass 
index (BMI) was calculated $\left(\mathrm{kg} / \mathrm{m}^{2}\right)$ and the cut-off value for normal BMI was considered as $25 \mathrm{~kg} / \mathrm{m}^{2} ; 25-29.9 \mathrm{~kg} /$ $\mathrm{m}^{2}$ were considered as overweight and $\geq 30 \mathrm{~kg} / \mathrm{m} 2$ were considered as obese as suggested by National Institute of Health (NIH). ${ }^{15}$ Waist circumference was measured midway between the lower rib and superior border of the iliac crest. Blood pressure was measured by using a sphygmomanometer. Further, the presence of MetS was determined based on diagnostic criteria provided by the NCEP ATP III 2004, IDF 2006, WHO 1998, AACE 2003 and Harmonized Joint Scientific Statement 2009. ${ }^{9}$

The Diabetes risk score of each individual was calculated by using the FINDRISC tool. The FINDRISC tool contains seven different variables, BMI, WC, daily physical activity, daily consumption of vegetables/fruits, anti-hypertensive medication, high blood sugar and relatives with T2DM. Each of the variables has a different grade to calculate the total number of diabetes score. ${ }^{16}$ Patients with an average of at least half an hour exercise daily were classified into high adherence to exercise. The history of the past 6 months regular alcohol use (at least 2 drinks per day) was classified as "Regular alcohol consumption". Occasional and nonsmokers were considered as "non-smoking and daily smokers were considered as Current Smoking".

Fasting ( 8 to 12 hours) venous blood was collected and serum was separated for biochemical analysis. Fasting blood samples were analyzed for glucose (FBG) total cholesterol (TC), triglyceride (TG), high-density lipoprotein cholesterol (HDL-C) and low-density lipoprotein cholesterol (LDL-C) as per the instructions provided by the reagent manufacturer (Agappe Diagnostics Switzerland $\mathrm{GmbH})$. All the parameters were analyzed using a Mispa
Viva (semi-automated Biochemistry analyzer, Agappe Diagnostics Switzerland $\mathrm{GmbH}$ ) in the Department of Biochemistry, MMIHS.

\section{Statistical Analysis}

Data were analysed using SPSS version 20.0 (IBM Corp., Armonk, NY, USA) and Microsoft Excel 2010. Independent Sample $t$-test was used to analyse mean comparison of baseline characteristics between male and female populations. Likewise, the risk factors based on FINDRISC score for Diabetes between males and females were analysed by chisquare test. Likewise, bivariate analysis was done to obtain the crude effect of risk factors (independent variables) on MetS and diabetes risk. Variables with $p$-values $<0.2$ enter into multivariable logistic regression analysis. The association between lifestyle risk factors with MetS and Diabetes was measured using odds ratio (OR) with $95 \%$ confidence Interval. The $p$-value of $<0.05$ was considered statistically significant in this study. Further, statistically significant differences of cardiometabolic risk factors with Diabetes Risk score were established by one-way ANOVA test.

\section{Results}

All the students (825) from Manmohan Memorial Institute of Health Science and Central Institute of Science and Technology were interviewed. Among them, 4 were not within the (18-25 years) age group and 31 students refuse to provide all the required information and anthropometric measurements. Fifty-one students did not provide the fasting blood sample the next morning for the biochemical measurements. Finally, 739 students were included as the study population in this study (Figure 1). Hence, the final

\section{5 students participated in the survey \\ 4 were not within the (18-25years) age group \\ 31 students refuse to provide required information \\ 790 students completed the questionnaire and measurement \\ 51 students did not provide the fasting blood sample \\ Total 739 student 's data was analyzed}

Figure I Flowchart of the study. 
Table I Baseline Characteristics of Different Study Population

\begin{tabular}{|c|c|c|c|c|}
\hline Parameters & Total $(n=739)$ & Male $(n=273)$ & Female $(n=466)$ & $P$ value ( $t$-test) \\
\hline Age (year) & $20.29 \pm 1.77$ & $20.73 \pm 1.90$ & $20.13 \pm 1.69$ & $0.4 I I(3.40)$ \\
\hline BMI $\left(\mathrm{kg} / \mathrm{m}^{2}\right)$ & $21.07 \pm 3.17$ & $21.61 \pm 3.40$ & $20.87 \pm 3.07$ & $0.210(2.33)$ \\
\hline$W C(\mathrm{~cm})$ & $79 . \mid 4 \pm 8.91$ & $81.18 \pm 8.35$ & $76.63 \pm 8.65$ & $<0.001 *(6.42)$ \\
\hline WHR & $0.88 \pm 0.05$ & $0.91 \pm 6.92$ & $0.88 \pm 0.05$ & $<0.001 *(7.1 \mathrm{I})$ \\
\hline $\mathrm{SBP}(\mathrm{mm}$ of $\mathrm{Hg})$ & $|04.68 \pm| 2.6 \mid$ & $1 \mid 3.89 \pm 11.79$ & $101.23 \pm 11.10$ & $<0.001 *(I I . I I)$ \\
\hline $\mathrm{DBP}(\mathrm{mm}$ of $\mathrm{Hg})$ & $70.70 \pm 7.9$ & $75.74 \pm 7.69$ & $68.81 \pm 7.12$ & $<0.001 *(9.44)$ \\
\hline FBS (mg/dl) & $85.62 \pm 12.20$ & $90.53 \pm 13.44$ & $83.78 \pm 11.19$ & $<0.00$ I* $(5.65)$ \\
\hline TC (mg/dl) & $|37.48 \pm 3| .16$ & $136.92 \pm 29.95$ & $|37.68 \pm 3| .64$ & $0.808(-0.24)$ \\
\hline TG (mg/dl) & $88.89 \pm 37.61$ & $95.70 \pm 43.06$ & $86.35 \pm 35.09$ & $0.014^{*}(2.48)$ \\
\hline HDL-C (mg/dl) & $41.60 \pm 9.20$ & $38.93 \pm 8.73$ & $42.60 \pm 9.19$ & $<0.001 *(-4.02)$ \\
\hline LDL-C (mg/dl) & $78.35 \pm 30.22$ & $79.15 \pm 28.63$ & $78.05 \pm 30.84$ & $0.718(0.36)$ \\
\hline VLDL-C (mg/dl) & $17.78 \pm 7.52$ & $|9| 4 \pm 8.6 \mid$. & $17.27 \pm 7.02$ & $0.014^{*}(2.21)$ \\
\hline
\end{tabular}

Note: *Represents the test is significant (test is considered significant if $p$ value is less than 0.05 ).

Abbreviations: BMI, body mass index; WC, waist circumference; WHR, waist-to-hip circumference ratio; SBP, systolic blood pressure; DBP, diastolic blood pressure; FBS, fasting blood glucose; TC, total cholesterol; TG, triglyceride; HDL-C, high-density lipoprotein cholesterol; LDL-C, low-density lipoprotein cholesterol; VLDL, very lowdensity lipoprotein.

analysis included 739 students' data of whom $273(36.9 \%)$ were male and $466(63.1 \%)$ were female.

Table 1 shows the baseline characteristics of the study population. Waist circumference (WC), waist-to-hip ratio (WHR), blood pressure (BP), fasting blood glucose (FBS), and triglyceride (TG) were significantly higher in male than in female, whereas high-density lipoproteins (HDLC) were significantly lower in male compared to female $(\mathrm{p}<0.05)$.

In our study population, the most prevalent defining component of metabolic syndrome was low HDL-C (78\%) followed by high waist circumference (31\%), elevated FBS (11.3\%), high TG (7.5\%) and hypertension (4.2\%). Based on the above components, $7.1 \%$ of young students were presented with MetS as defined by Harmonized Joint Scientific Statement (HJSS) criteria, followed by $5.8 \%$ (IDF), 4.0\% (NCEP ATP III), 3.6\% (WHO) and 2.3\% (AACE). The prevalence of MetS was found to be significantly higher in males compared to females except for the HJSS and IDF criteria and the prevalence was significantly equal using NCEP ATP III criteria (Table 2).

Further, different risk factors were assessed for the FINDRISC points to define the different grades of risk of diabetes in our study population (Table 3). Based on the FINDRISC score, 553 (74.80\%) were under low risk for diabetes (Score <7). Among the total population 164 $(22.18 \%)$ had slightly elevated risk (Score between 7 and 11), $15(2.02 \%)$ had moderate risk (Score between 12 and 14 ) and $7(1.01 \%)$ had a high risk of diabetes (Score between 15 and 20). Male had significantly higher FINDRISC score as compared to female ( $\mathrm{p}$ 0.002) (Figure 2). Different lifestyle risk factors for MetS and T2DM were measured using bivariate analysis. A stepwise backward elimination procedure was applied with variables with p-value less than 0.2 in multivariable logistic analysis to calculate the adjusted odds ratio (AOR). Among all the independent variables, only current smoking (AOR, 4.49, 95\% CI 1.38-14.62) was the independent risk factor for MetS and only low adherence to physical exercise (AOR, 4.81, 95\% CI, 2.90-7.99) was an independent risk for T2DM (Table 4). Table 5 illustrates the association of cardiometabolic risk with FINDRISC score. There was a significant increase in BMI $(\mathrm{p}<0.001), \mathrm{TC}(\mathrm{p}=0.04)$, and LDL-C $(p=0.008)$ with increase in FINDRISC score.

\section{Discussions}

There is a common fallacy that the young populations are in their active phase of life and are less prone to develop

Table 2 Prevalence of Metabolic Syndrome in Study Population

\begin{tabular}{|l|l|l|l|}
\hline Criteria & $\begin{array}{l}\text { Prevalence of } \\
\text { MetS } \\
\text { (Total=739) }\end{array}$ & $\begin{array}{l}\text { Male } \\
\mathbf{( 2 7 3 )}\end{array}$ & $\begin{array}{l}\text { Female } \\
\mathbf{( 4 6 6 )}\end{array}$ \\
\hline HJSS & $27(7 \%)$ & $14(51.85 \%)$ & $13(48.15 \%)$ \\
IDF & $43(5.8 \%)$ & $12(27.9 \%)$ & $31(72.1 \%)$ \\
NCEP ATP III & $30(4 \%)$ & $15(50 \%)$ & $15(50 \%)$ \\
WHO & $27(3.6 \%)$ & $14(51.85 \%)$ & $13(48.15 \%)$ \\
AACE & $17(2.3 \%)$ & $12(70.5 \%)$ & $5(29.5 \%)$ \\
\hline
\end{tabular}

Abbreviations: MetS, metabolic syndrome; HJSS, Harmonized Joint Scientific Statement; IDF, International Diabetic Federation; NCEP ATP III, National Cholesterol Education Program Adult Treatment Pannel III; WHO, World Health Organisation; AACE, American Association of Clinical Endocrinologists. 
Table 3 Risk Factors for Type 2 Diabetes Mellitus Among Study Population

\begin{tabular}{|c|c|c|c|c|c|}
\hline Variables & FINDRISC Points & $\begin{array}{l}\text { Total (\%) } \\
(n=739)\end{array}$ & $\begin{array}{l}\text { Male (\%) } \\
(n=273)\end{array}$ & $\begin{array}{l}\text { Female }(\%) \\
(n=466)\end{array}$ & $P$ value $\left(X^{2}\right)$ \\
\hline \multicolumn{6}{|l|}{ BMI $(\mathrm{kg} / \mathrm{m} 2)$} \\
\hline$<25.0$ & 0 & 654(88.5) & $231(84.6)$ & $420(90.1)$ & $0.206(3.16)$ \\
\hline $25.0-29.9$ & I & $74(10.1)$ & $36(13.2)$ & $4 I(8.8)$ & \\
\hline$\geq 30.0$ & 3 & $\mathrm{II}(\mathrm{I} .4)$ & $6(2.2)$ & $5(1.1)$ & \\
\hline \multicolumn{6}{|l|}{ WC (cm) } \\
\hline$<94(\mathrm{M}),<80(\mathrm{~F})$ & 0 & $533(72.12)$ & $25 I(91.9)$ & $303(65.02)$ & $<0.00 I(30.82)$ \\
\hline $94-102(M) / 80-88(F)$ & 3 & $152(20.57)$ & $16(5.9)$ & $|2|(25.97)$ & \\
\hline$>102(\mathrm{M}) / 88(\mathrm{~F})$ & 4 & $54(7.30)$ & $6(2.2)$ & $42(9.01)$ & \\
\hline \multicolumn{6}{|l|}{ Physical activity (30min/day) } \\
\hline Yes & 0 & $402(54.40)$ & $168(61.54)$ & $24 I(5 I .72)$ & $0.054(3.7 I)$ \\
\hline No & 2 & $337(45.60)$ & $105(38.46)$ & $225(48.28)$ & \\
\hline \multicolumn{6}{|l|}{ Vegetables/fruits (100mg/day) } \\
\hline Yes & 0 & $119(16.10)$ & $30(11.0)$ & $84(18.0)$ & $0.063(3.45)$ \\
\hline No & I & $620(83.90)$ & $243(89.0)$ & $382(82.0)$ & \\
\hline
\end{tabular}

Note: $X^{2}$ represents the $t$-test value.

Abbreviations: BMI, body mass index; WC, waist circumference; M, male; F, female; DM, diabetes mellitus.

MetS. Nonetheless, our study revealed the overall frequency distribution of MetS was found to be $7.1 \%$, $5.8 \%, 4.0 \%, 3.6 \%$ and $2.2 \%$ according to definitions provided by Harmonized Joint Scientific Statement (HJSS), International Diabetes Federation (IDF), National
Cholesterol Education Programme Adult Treatment Panel III (NCEP ATP III), World Health Organization (WHO) and American Association of Clinical Endocrinologists (AACE) in young adults. The prevalence of MetS obtained from this study is higher than the findings by Mbugua et al

\section{घale $n$ female}

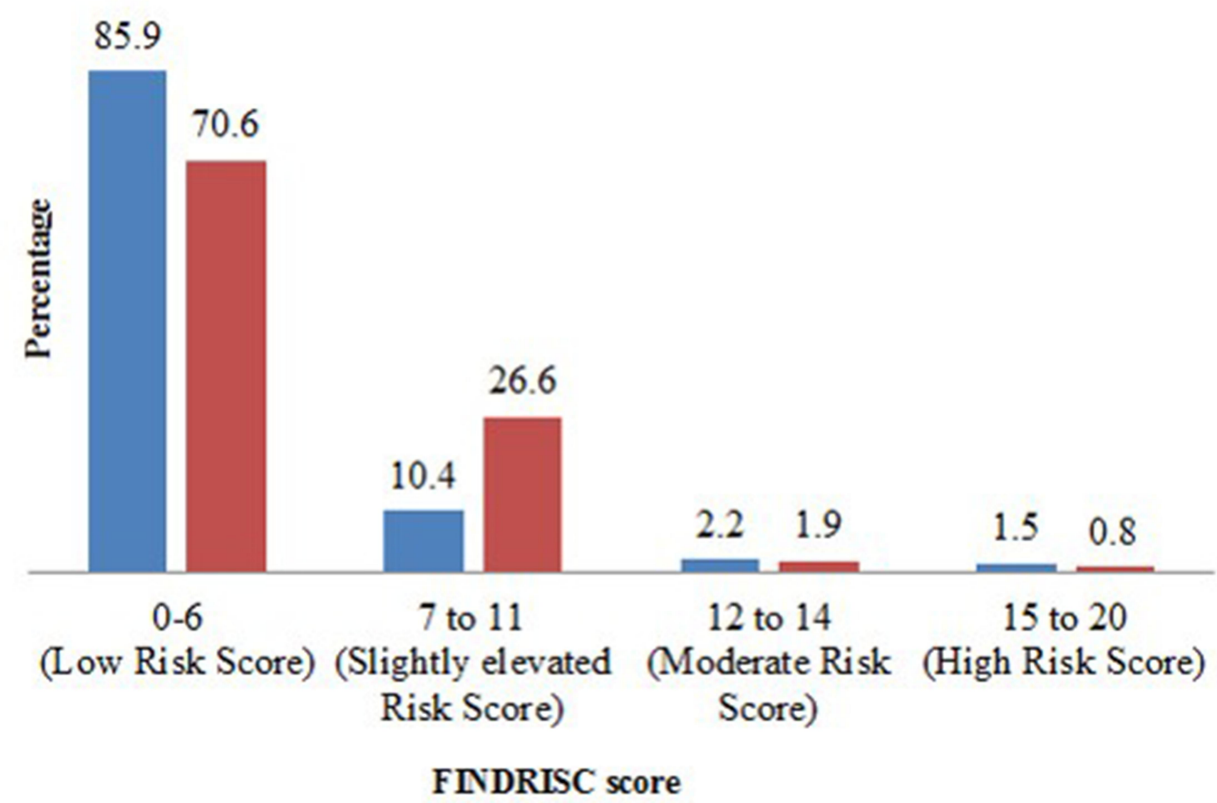

Figure 2 Risk assessment by FINDRISC score. 
Table 4 Lifestyle Risk Factors for Metabolic Syndrome and Diabetes Among Study Population

\begin{tabular}{|c|c|c|c|c|c|c|c|c|c|}
\hline \multicolumn{2}{|l|}{ Variables } & \multicolumn{4}{|c|}{ MetS(+) HJSS Criteria } & \multicolumn{4}{|c|}{ Diabetes Risk (FINDRISC>7) } \\
\hline & & $\begin{array}{l}\text { COR } \\
(95 \% \mathrm{CI})\end{array}$ & p-value & $\begin{array}{l}\text { AOR } \\
(95 \% \mathrm{CI})\end{array}$ & p-value & $\begin{array}{l}\text { COR } \\
(95 \% \mathrm{CI})\end{array}$ & p-value & $\begin{array}{l}\text { AOR } \\
(95 \% \mathrm{CI})\end{array}$ & p-value \\
\hline Regular Alcohol consumption & $\begin{array}{l}\text { Yes } \\
\text { No }\end{array}$ & $\begin{array}{l}1.47 \\
(0.74-2.94)\end{array}$ & 0.187 & - & & $\begin{array}{l}0.94 \\
(0.6 \mathrm{I}-2.47)\end{array}$ & 0.982 & - & \\
\hline Current Smoking & $\begin{array}{l}\text { Yes } \\
\text { No }\end{array}$ & $\begin{array}{l}4.96 \\
(1.69-14.56)\end{array}$ & 0.004 & $\begin{array}{l}4.49 \\
(I .38 I-\mid 4.62 I)\end{array}$ & 0.013 & $\begin{array}{l}0.48 \\
(0.18-1.32)\end{array}$ & 0.166 & $\begin{array}{l}0.37 \\
(0.12-1.10)\end{array}$ & 0.073 \\
\hline $\begin{array}{l}\text { Daily inclusion of green } \\
\text { vegetables and fruits in diet }\end{array}$ & $\begin{array}{l}\text { Yes } \\
\text { No }\end{array}$ & $\begin{array}{l}0.79 \\
(0.23-2.67)\end{array}$ & 0.991 & - & & $\begin{array}{l}0.525 \\
(0.26-1.06)\end{array}$ & 0.196 & $\begin{array}{l}0.71 \\
(0.34-1.49)\end{array}$ & 0.542 \\
\hline Physical activity & $\begin{array}{l}\text { High Adherence } \\
\text { Low adherence }\end{array}$ & $\begin{array}{l}0.69 \\
(0.26-1.82)\end{array}$ & 0.450 & - & & $\begin{array}{l}4.77 \\
(2.90-7.84)\end{array}$ & $<0.001$ & $\begin{array}{l}4.81 \\
(2.90-7.99)\end{array}$ & $<0.001$ \\
\hline
\end{tabular}

Abbreviations: COR, crude odds ratio; AOR, adjusted odds ratio; HJSS, Harmonized Joint Scientific Statement.

Table 5 Association of Cardiometabolic Risk with Diabetes Risk Score

\begin{tabular}{|c|c|c|c|c|c|}
\hline Parameter & $\begin{array}{l}\text { Low Risk } \\
(F<7) \\
(n=553)\end{array}$ & $\begin{array}{l}\text { Slightly Elevated } \\
\text { Risk (F 7-I I) } \\
(n=164)\end{array}$ & $\begin{array}{l}\text { Moderate Risk } \\
(F \mid 2-14) \\
(n=\mid 5)\end{array}$ & $\begin{array}{l}\text { High Risk (FI5-20) } \\
(n=7)\end{array}$ & $p$ for Trend \\
\hline Age (years) & $20.34 \pm 1.78$ & $20.04 \pm 1.77$ & $20.80 \pm 1.32$ & $21.2 \pm 0.84$ & 0.201 \\
\hline BMI $\left(\mathrm{kg} / \mathrm{m}^{2}\right)$ & $20.46 \pm 2.60$ & $22.37 \pm 3.48$ & $25.96 \pm 5.10$ & $28.24 \pm 5.27$ & $<0.00 I^{*}$ \\
\hline SBP $(\mathrm{mmHg})$ & $104.03 \pm 12.0$ & $106.36 \pm 11.92$ & $109.0 \pm 11.97$ & $107.0 \pm 12.04$ & 0.232 \\
\hline $\mathrm{DBP}(\mathrm{mmHg})$ & $70.16 \pm 8.07$ & $72.32 \pm 6.70$ & $73.0 \pm 9.49$ & $70.0 \pm 7.07$ & 0.065 \\
\hline FBG (mg/dl) & $85.12 \pm 10.68$ & $84.36 \pm|2.9|$ & $103.1 \pm 22.41$ & $115 \pm 17.35$ & $<0.00 I^{*}$ \\
\hline TC (mg/dl) & $135.09 \pm 28.26$ & $|42.89 \pm 35.6|$ & $164.9 \pm 57.68$ & $140.4 \pm 32.0$ & $0.004^{*}$ \\
\hline TG (mg/dl) & $87.5 I \pm 36.73$ & $91.66 \pm 40.19$ & $94.8 \pm 39.56$ & $119 \pm 33.82$ & 0.208 \\
\hline HDL-C (mg/dl) & $41.22 \pm 9.18$ & $42.99 \pm 9.63$ & $40.6 \pm 5.84$ & $41.80 \pm 5.4$ & 0.353 \\
\hline LDL-C (mg/dl) & $76.36 \pm 27.67$ & $82.77 \pm 34.60$ & $105.12 \pm 53.44$ & $74.80 \pm 21.02$ & $0.008^{*}$ \\
\hline TC/HDL ratio & $3.42 \pm 1.01$ & $3.49 \pm 1.25$ & $4.14 \pm 1.55$ & $3.33 \pm 0.36$ & 0.206 \\
\hline LDL/HDL ratio & $1.97 \pm 0.89$ & $2.06 \pm 1.11$ & $2.65 \pm 1.38$ & $1.77 \pm 0.29$ & 0.131 \\
\hline
\end{tabular}

Note: *Represents the test is significant at $5 \%$ level of significance.

Abbreviations: F, FINDRISC; BMI, body mass index; SBP, systolic blood pressure; DBP, diastolic blood pressure; FBS, fasting blood glucose; TC, total cholesterol; TG, triglyceride; HDL-C, high-density lipoprotein cholesterol; LDL, low-density lipoprotein cholesterol.

$(1.9 \%)$ in Kenya (East Africa) $)^{3}$ and Manjunath et al $(6.6 \%)$ in India, ${ }^{17}$ while lower than the study performed by Tope and Rogers $(9.3 \%)$ in the USA. ${ }^{18}$ The disparity and inconsistency in MetS prevalence could be because of differences in the study population, lifestyle choices, dietary habits, genetic factors and socioeconomic status. In addition, the investigation methods and MetS criteria used also has a significant role in such disparities.

The most prevalent defining component for MetS was reduced HDL-C (78\%) followed by abdominal obesity (31\%) with hypertension (4.2\%) being the least prevalent. Significantly, more males were found to meet the MetS diagnostic criteria compared to their female counterparts according to the WHO, NCEP ATP III, AACE definitions. Increased rate of engagement in smoking among males in our study could be one potential reason for this difference. Likewise, the endogenous estrogen in females has a cardio-protective role, which likely explains this difference. ${ }^{19}$ Abdominal obesity was found to be the second most prevalent component in our study population according to the ethnic-specific criteria given by IDF. The Nepal Non-Communicable Disease Risk Factor Survey, 2007 was based on a nationally representative study including all three ecological regions reported average waist circumference to be $74.9 \mathrm{~cm}$ in males and $70.3 \mathrm{~cm}$ in females. ${ }^{2}$ Compared to this finding of the National survey, our study showed average waist circumference to be $81.18 \pm 8.35$ in males and $76.63 \pm 8.65$ in females. The relatively lower prevalence of central obesity in our population following NCEP ATP III criteria is due 
to the higher cut-off value of WC; this may underestimate the prevalence of MetS in our populations, which we have discussed in our previous research. ${ }^{20}$ Differing methodologies and sample sizes also probably explain this difference. Since abdominal obesity is recognized as an independent risk factor for the development of CVDs, it can be inferred from the above data that $31 \%$ of young students participating in our study are under CVDs risk.

Out of 739 participants in our study, 56.5\% consumed alcohol, $22.4 \%$ were regular smokers and only $16.13 \%$ included green vegetables and fruits in their daily diet (data not shown). It has been reported, that vegetables and fruits are mainly responsible for the protection against hypertension and cardiovascular diseases. Moreover, antioxidants present in vegetables and fruits inactivate the effects of free radicals and lipid peroxidation, which could affect arterial stiffness. ${ }^{21}$ Similarly, smoking was obtained as an independent risk factor for MetS with an OR of 4.95 (95\% CI 1.68-14.55) in our study. Previous findings have shown that smoking is positively related to BMI and waist-to-hip ratio ${ }^{22}$ and thus increases the risk of abdominal obesity. ${ }^{23}$ Also, nicotine acts as an adrenergic agonist, which leads to an increased release of vasopressin, resulting in an acute increase in both blood pressure and heart rate. ${ }^{24}$ The relatively higher prevalence of MetS in our population may be due to these unhealthy dietary behaviors.

It is well demonstrated that each component of MetS has an association with many clinical conditions like T2DM, CVD, NAFLD, etc. In our previous studies, we detect the prevalence of MetS in patients with NAFLD and T2DM. ${ }^{8,20}$ Different clinical trials have reported MetS as a predictor of new-onset of type 2 diabetes. Therefore, early detection of MetS in adult individuals is essential not only for the prevention of MetS itself but also to deter associated complications like T2DM, NAFLD and CVDs. $^{25}$

Our study showed that $22.2 \%$ of total students had a slightly elevated risk, $2.02 \%$ had a moderate risk and $1.01 \%$ had a high risk of developing T2DM in the near future based on FINDRISC score. A similar study conducted by S. Al-Shudifat et al in the young student population in Jordan resulted that $26.2 \%$ had a slightly elevated risk, $5.2 \%$ had a moderate risk and $1.8 \%$ had a high risk for $\mathrm{T} 2 \mathrm{DM},{ }^{26}$ which is slightly higher to our study. It is well known that regular physical activity for at least 30 minutes reduces diabetes risk from $35 \%-40 \%{ }^{27,28}$ We found that low adherence to exercise was an independent variable $(\mathrm{AOR}=4.81)$ for the diabetes risk. Therefore, a possible reason for fewer individuals having a high risk of T2DM in our study may be due to their higher participation in physical activities (54.4\%). Our study ensued first-degree and second-degree family history of diabetes in only about $21.8 \%$ and $38.5 \%$ of total students, respectively, and obesity was present in $27.8 \%$ of students. The trend of diabetes risk, when compared to some studies in a higher age group, was drastically higher. Martin et al revealed that $15.9 \%$ were at slightly elevated risk, $42.9 \%$ were at moderate risk and $33.5 \%$ were at high risk for diabetes. ${ }^{29}$ Similarly, Jeroen De Cocker showed $10.3 \%$ with moderate risk and $10.4 \%$ with a high risk of diabetes (35-55years). ${ }^{11}$ This may be due to advancing age during which they are already exposed to risk factors associated with diabetes and this result highlights the importance of determining the diabetes risk in the early adult phase to reduce future diabetes.

It is notable that risk factors for MetS are also the risk factors for T2DM and are also the risk factors for cardiovascular diseases. ${ }^{30}$ In accordance with this, we examined the association of cardiovascular risk with diabetes risk. It showed that the mean FINDRISC increase was significantly associated with hyperglycaemia and hypercholesterolemia. There was significant increase in BMI and TG with an increase in the diabetes risk score. Likewise, HDL-C was found significantly decrease with an increase in the diabetes risk score. In comparison, there was a significant increase in mean fasting blood glucose, total cholesterol, LDL-C, and BMI with an increase in diabetes risk score in validation study performed by Makrilakis et al (2011), ${ }^{12}$ which was similar to our study. In discordance, there was a significant increase in triglyceride and a decrease in HDL-C in their study. The significant rise in BMI and atherogenic lipids (TC and LDL-C) with an increase in the FINDRISC score predicts the risk of CVDs in a near future in our diabetes risk populations.

This study Limits only Health Sciences students predominantly in one specific age group studying in the Capital City that possibly have high-risk factors for MetS. The inclusion of more young adults from different parts of the country would facilitate the intervention policy for high-risk young individuals.

\section{Conclusion}

Current smoking was the independent risk factor for MetS and low adherence to physical exercise was an independent risk for T2DM. This report has demonstrated that metabolic syndrome is present, although in low numbers in young 
adults putting them at risk to develop diabetes in the near future. It is therefore essentially an early assessment of diabetes and metabolic risk in young. In addition, cardiometabolic risks are associated with an increased risk of diabetes. This study may provide insight for preventive and control plans for the population with future diabetes risk of CVDs.

\section{Data Sharing Statement}

All the data generated during this study are presented in this paper. The primary raw data will be made available to interested researchers by the corresponding author if requested.

\section{Ethical Approval and Consent to Participate}

This research was approved by the Institutional Review Committee of Manmohan Memorial Institute of Health Sciences (IRC MMIHS), Kathmandu, Nepal (letter of approval Ref No: 217/MMIHS/2075). This work was conducted in accordance with the Helsinki Declaration. Informed and written consent was taken from each participant in this study. Data regarding personal information were coded and kept confidential.

\section{Consent for Publication}

Informed and written consent was obtained from every students enrolled in the study.

\section{Author Contributions}

All authors made a significant contribution to the design of the study, data analysis, interpretation of data, drafting or revising the article, gave final approval of the version to be published and agree to be accountable for all aspects of the work.

\section{Funding}

There was no any monetary benefit received from any agency for this study.

\section{Disclosure}

The authors declare that they have no competing interests.

\section{References}

1. Eapen D, Kalra GL, Merchant N, et al. Metabolic syndrome and cardiovascular disease in South Asians. Vasc Health Risk Manag. 2009;5:731-743. doi:10.2147/vhrm.s5172

2. Vaidya A, Shakya S, Krettek A. Obesity prevalence in Nepal: public health challenges in a low-income nation during an alarming worldwide trend. Int J Environ Res Public Health. 2010;7(6):2726-2744. doi:10.3390/ijerph7062726
3. Mbugua SM, Kimani ST, Munyoki G. Metabolic syndrome and its components among university students in Kenya. BMC Public Health. 2017;17(1):909. doi:10.1186/s12889-017-4936-x

4. Sharma SK, Ghimire A, Radhakrishnan J, et al. Prevalence of hypertension, obesity, diabetes, and metabolic syndrome in Nepal. Int J Hypertens. 2011;2011:821971. doi:10.4061/2011/821971

5. Kelli HM, Kassas I, Lattouf OM. Cardio metabolic syndrome: a global epidemic. J Diabetes Metab. 2015;6(3):2-14. doi:10.4172/ 2155-6156.1000513

6. Federation ID. The IDF consensus worldwide definition of the metabolic syndrome. 2006. Available from: https://www.idf.org/e-library/ consensus-statements/60-idfconsensus-worldwide-definitionof-themetabolic-syndrome. Accessed August 3, 2020.

7. Alberti KG, Zimmet PZ. Definition, diagnosis and classification of diabetes mellitus and its complications. Part 1: diagnosis and classification of diabetes mellitus provisional report of a WHO consultation. Diabet Med. 1998;15(7):539-553. doi:10.1002/ (SICI)1096-9136(199807)15:7<539::AID-DIA668>3.0.CO;2-S

8. Pardhe BD, Shakya S, Bhetwal A, et al. Metabolic syndrome and biochemical changes among non-alcoholic fatty liver disease patients attending a tertiary care hospital of Nepal. BMC Gastroenterol. 2018;18(1):109. doi:10.1186/s12876-018-0843-6

9. Alberti KG, Eckel RH, Grundy SM, et al. Harmonizing the metabolic syndrome. A joint interim statement of the international diabetes federation task force on epidemiology and prevention; national heart, lung, and blood institute; american heart association; world heart federation; international atherosclerosis society; and international association for the study of obesity. Circulation. 2009;120:1640-1645. doi:10.1161/CIRCULATIONAHA.109.192 644

10. Kerner W, Bruckel J. Definition, classification and diagnosis of diabetes mellitus. Exp Clin Endocrinol Diabetes. 2014;122 (7):384-386. doi:10.1055/s-0034-1366278

11. De cocker J. Validation of the Finnish diabetes risk score (Findrisc) for diabetes screening in the Belgian population. 2015-2016. Accessed from: https://lib.ugent.be/fulltxt/RUG01/002/304/550/ RUG01002304550_2016_0001_AC.pdf.

12. Makrilakis K, Liatis S, Grammatikou S, et al. Validation of the Finnish diabetes risk score (FINDRISC) questionnaire for screening for undiagnosed type 2 diabetes, dysglycaemia and the metabolic syndrome in Greece. Diabetes Metab. 2011;37(2):144-151. doi:10.1016/j.diabet.2010.09.006

13. Cha E, Paul S, Braxter BJ, et al. Dietary behaviors and glucose metabolism in young adults at risk for type 2 diabetes. Diabetes Educ. 2018;44(2):158-167. doi:10.1177/0145721718756057

14. Clark RL, Famodu OA, Holásková I, et al. Educational intervention improves fruit and vegetable intake in young adults with metabolic syndrome components. Nutr Res. 2019;62:89-100. doi:10.1016/j. nutres.2018.11.010

15. National Heart L, and Blood Institute(NIH). Overweight and obesity. 2019. Available from: https://www.nhlbi.nih.gov/health-topics/over weight-and-obesity. Accessed August 3, 2020.

16. Al-Shudifat A-E, Al-Shdaifat A, Al-Abdouh AA, et al. Diabetes risk score in a young student population in Jordan: a cross-sectional study. J Diabetes Res. 2017;2017:5. doi:10.1155/2017/8290710

17. Manjunath D, Uthappa CK, Kattula SR, et al. Metabolic syndrome among urban Indian young adults: prevalence and associated risk factors. Metab Syndr Relat Disord. 2014;12(7):381-389. doi:10.1089/met.2014.0003

18. Topè AM, Rogers PF. Metabolic syndrome among students attending a historically black college: prevalence and gender differences. Diabetol Metab Syndr. 2013;5(1):2. doi:10.1186/ 1758-5996-5-2

19. Mendelsohn ME, Karas RH. The protective effects of estrogen on the cardiovascular system. N Engl J Med. 1999;340(23):1801-1811. doi:10.1056/NEJM199906103402306 
20. Pardhe BD, Kapali OS, Mathias J, et al. Elevated liver transaminases and their association with metabolic syndrome in type 2 diabetic patients attending tertiary care hospital of Nepal. Clin Lipidol. 2018;13(1):4-12.

21. Psaltopoulou T, Naska A, Orfanos P, et al. Olive oil, the mediterranean diet, and arterial blood pressure: the Greek European prospective investigation into cancer and nutrition (EPIC) study. Am J Clin Nutr. 2004;80(4):1012-1018. doi:10.1093/ajcn/80.4.1012

22. Chiolero A, Jacot-Sadowski I, Faeh D, et al. Association of cigarettes smoked daily with obesity in a general adult population. Obesity. 2007;15(5):1311-1318. doi:10.1038/oby.2007.153

23. Saarni SE, Pietiläinen K, Kantonen S, et al. Association of smoking in adolescence with abdominal obesity in adulthood: a follow-up study of 5 birth cohorts of Finnish twins. Am J Public Health. 2009;99(2):348-354. doi:10.2105/AJPH.2007.123851

24. Cryer PE, Haymond MW, Santiago JV, et al. Norepinephrine and epinephrine release and adrenergic mediation of smoking-associated hemodynamic and metabolic events. $N$ Engl J Med. 1976;295 (11):573-577. doi:10.1056/NEJM197609092951101

25. Shin J-A, Lee J-H, Lim S-Y, et al. Metabolic syndrome as a predictor of type 2 diabetes, and its clinical interpretations and usefulness. J Diabetes Investig. 2013;4(4):334-343. doi:10.1111/jdi.12075
26. Al-Shudifat AE, Al-Shdaifat A, Al-Abdouh AA, et al. Diabetes risk score in a young student population in Jordan: a cross-sectional study. J Diabetes Res. 2017;2017:8290710.

27. Chien K-L, Hsu H-C, Su T-C, et al. Fasting and postchallenge hyperglycemia and risk of cardiovascular disease in Chinese: the Chin-Shan community cardiovascular cohort study. Am Heart J. 2008;156(5):996-1002. doi:10.1016/j.ahj.2008.06.019

28. Alberti KG, Zimmet P, Shaw J. The metabolic syndrome-a new worldwide definition. Lancet. 2005;366(9491):1059-1062. doi:10.1016/S0140-6736(05)67402-8

29. Martin E, Ruf E, Landgraf R, et al. FINDRISK questionnaire combined with HbAlc testing as a potential screening strategy for undiagnosed diabetes in a healthy population. Horm Metab Res. 2011;43(11):782-787. doi:10.1055/s-0031-1286333

30. D'Souza MS, Amirtharaj A, Venkatesaperumal R, et al. Riskassessment score for screening diabetes mellitus among Oman adults. SAGE Open Med. 2013;1:2050312113508390. doi:10.1177/ 2050312113508390
Drug, Healthcare and Patient Safety

\section{Publish your work in this journal}

Drug, Healthcare and Patient Safety is an international, peer-reviewed open-access journal exploring patient safety issues in the healthcare continuum from diagnostic and screening interventions through to treatment, drug therapy and surgery. The journal is characterized by the rapid reporting of reviews, original research, clinical, epidemiological and post-marketing surveillance studies, risk management, health

\section{Dovepress}

literacy and educational programs across all areas of healthcare delivery. The manuscript management system is completely online and includes a very quick and fair peer-review system. Visit http://www.dovepress.com/testimonials.php to read real quotes from published authors. 